\title{
End-User Understanding of Subject Headings in Library Catalogs
}

\section{Karen M. Drabenstott, Schelle Simcox, and Eileen G. Fenton}

\begin{abstract}
In this article, we report on the first large-scale study of end-user understanding of subject headings. Our objectives were to determine the extent to which children and adults understood subdivided subject headings and to suggest improvements for improving understanding of subject headings. The 1991 Library of Congress Subject Subdivisions Conference suggested standardizing the order of subject subdivisions for the purpose of simplifying subject cataloging, which served as the impetus for the study. We demonstrated that adults understood subject headings better than children; however, both adults and children assigned correct meanings to less than half of the subject headings they examined. Neither subject heading context nor subdivision order had an effect on understanding. Based on our findings, we challenge the library community to make major changes to the Library of Congress Subject Headings system that have the potential to increase end-user understanding of subject headings.
\end{abstract}

A

ccording to Cutter (1904), the most important subject cataloging principle is consideration of the best interest of the catalog user. He stated (6): "The convenience of the public is always to be set before the ease of the cataloger."

In the 90 years since Cutter laid down this rule, the Library of Congress Subject

Headings (LCSH), the primary tool librarians consult for subject cataloging, has grown from a single volume listing a few thousand subject headings to a 5 -volume set listing about 200,000 subject headings. In libraries throughout the country, librarians have produced tens of millions of unique cataloging records

KAREn M. Drabenstott (karen.drabenstott@umich.edu) is associate professor, School of Information, University of Michigan, Ann Arbor. SCHELLE SIMCOX (simcox@library.monterey.edu) is reference and instructional services librarian, California State University, Monterey Bay, Seaside. EILEEN G. FENTON (egfenton@engin.umich.edu) is JSTOR production coordinator in Ann Arbor. We thank the OCLC Online Computer Library Center, Inc., which provided support for the study through its Library and Information Science Research Grant Program. We are especially grateful to: Gloria Coles, director, Flint Public Library, Michigan; Barbara Wallace, director, Bacon Memorial District Library, Michigan; and Michael Deller, director, Livonia Public Library, Michigan, who welcomed the study team to their libraries. The hard work and dedication of Bonnie A. Dede, Marie Williams, Melanie Leavitt, and Alaina Scopp streamlined data collection and analysis. Manuscript received January 6, 1999; accepted for publication March 2, 1999. 
bearing subject headings drawn from this subject-cataloging tool. Yet not once in that time have catalogers asked library users whether they understood the subject headings assigned to cataloging recordsnor did catalogers ask library users to suggest subject headings to represent the subject matter of the topics they seek.

In this article, we describe our large-scale empirical study of end-user understanding of subject headings. In the study, we focused on subdivided subject headings because the vast majority of subject headings in bibliographic files are subdivided (Drabenstott and VizineGoetz 1994). We addressed five research questions:

1. To what extent do end users understand subject headings?

2. Does end-user understanding vary based on subject heading context?

3. Does end-user understanding vary based on subject heading form?

4. Are there differences in levels of understanding between two types of end users (children and adults) and in levels of understanding for the different forms or contexts of subject headings?

5 . What changes should be made to $L C S H$ specifically and controlled vocabularies generally to improve end-user understanding of subject headings?

\section{LITERATURE REVIEW}

\section{The User AND Usage}

Haykin (1951) established the principle of the reader as a focus. He stated (7):

[T] he reader is the focus in all cataloging principles and practice. All other considerations, such as convenience and the desire to arrange entries in some logical order, are secondary to the basic rule that the heading, in wording and structure, should be that which the reader will seek in the cata$\log$, if we know or can presume what the reader will look under.

Chan $(1986,18)$ acknowledged that the meaning of Haykin's principle was "self-evident, but how to make it operational is not. The problem is delineating the user." Cutter and Haykin took different approaches to naming subjects in the catalog. Cutter (1904) recommended that public use be the guiding principle. Haykin $(1951,8)$ recommended "common usage or, at any rate, the usage of the class of reader for whom the material on the subject within which the heading falls is intended." In contrast to Cutter's straightforward approach, Haykin's approach gave the cataloger the freedom of naming subjects in the catalog based on the audience addressed by the material itself.

\section{New Subject Headings in LCSH}

The addition of new subject headings to $L C S H$ is the responsibility of an editorial group composed of Library of Congress (LC) staff members from the Cataloging Policy and Support Office and interested internal observers. The editorial group reviews proposals for changes to existing headings, i.e., "additions to, alterations in, or deletions of existing headings, heading/subdivision combinations, cross references, or free-floating subdivisions" (Chan 1995, 146). The group also considers new subject headings and "deliberates on terminology (wording), cross-references, notes, compatibility with descriptive headings (if applicable), and conformity to existing patterns and broad policies governing LCSH" (Chan 1995, 146).

Until very recently, proposals for new headings and changes to existing headings emanated exclusively from catalogers at LC. The Vocabulary Improvement Project (Cochrane 1983) and an initiative sponsored by the Subject Analysis Committee (SAC) Subcommittee on New Subject Headings were pilot projects that demonstrated to LC that librarians at institutions other than LC could propose see references and new subject headings using the same procedures that LC librarians followed. Today, LC encourages librarians to submit new subject headings and See references by following the guidelines in the Subject Cataloging Manual: Subject Headings (SCM:SH) (Library of Congress 1991, H180-203). Despite such encouragement, very few subject heading proposals emanate from outside LC (Cooperative Subject Cataloging Project 1991). 
In naming new subjects, LC catalogers face a more difficult task than their predecessors because of the diversity of today's catalog users. The decision to establish a new subject heading must take into consideration the best interest of users and the usage of the class of reader for whom the material is intended, and must avoid the use of terminology offensive to segments of the public. When Cutter proposed his principle of the best interest of the user, he did not have a problem knowing users and usage because library users were a homogeneous group (Miksa 1983). Although today's user population is much more diverse than the user population was in Cutter's day, today's catalogers have tools to aid in the naming of subjects that their predecessors could not have imagined. For example, catalogers can examine an online catalog's transaction log to identify user queries that fail to retrieve records; they can then determine whether these queries should be represented in the controlled vocabulary as established headings or See references. Or catalogers can analyze catalog users' answers to online questionnaires in which users are asked questions about their interests, overall objectives, search requests, and the usefulness of search results. Before online systems, researchers and library practitioners did not have an accurate and systematic method of determining the subjects that users had difficulty finding in library catalogs.

\section{END-USER UNDERSTANDING OF GATALOG INFORMATION}

Bates (1977) demonstrated that users knowledgeable in a particular subject are as successful retrieving citations from the catalog as users without such knowledge. Interestingly, Bates found that the most successful users are those without subject expertise but with knowledge of the structure and content of the catalog.

Missing from the published literature on catalog use are studies of end-user understanding of subject headings. Researchers who examine the subject queries that online catalog users enter into catalogs provide us with an estimation of end-user understanding of catalog information. These researchers have demonstrated that users were not very successful at matching their queries for topical subjects or geographic names with the catalog's controlled vocabulary (Drabenstott and Vizine-Goetz 1994; Carlyle 1989), and even less successful at matching subject queries for personal names and combinations of topical subjects and names (Drabenstott and Vizine-Goetz 1994; Lester 1989).

Lilly (1954) provides some insight into end-user understanding of catalog information. He supplied students with the titles and authors of six books and instructed them to write down the subject headings under which they would expect to find each book. The percentages of correct student responses ranged from $2 \%$ to $64 \%$.

\section{IMPETUS FOR RESEARCH ON \\ UndERSTANDING SUBJECT HEAdINGS}

Following the publication of the LC Subject Subdivisions Conference's recommendations (Conway 1992), SAC established and charged the Subcommittee on the Order of LCSH Subdivisions to respond to the first of six recommendations of the LC Subject Subdivisions Conference. In this recommendation, it was suggested that the order of subject subdivisions be standardized for the purpose of simplifying subject cataloging: "If the cataloger chooses to apply subdivisions, the subdivisions should always appear in the following order: topical, geographic, chronological, form" (Conway 1992,6 ). For three years, beginning with ALA's annual meeting in summer 1993, the subcommittee engaged in a multi-faceted study of the $L C S H$ subject subdivisions system to ensure an informed decision regarding the future of subject subdivisions. Franz et al. (1994) reported on a pilot test of end-user understanding of subdivided subject headings that was conducted in connection with the subcommittee's work.

Pilot test researchers concluded that between $32 \%$ and $40 \%$ of end-user responses were correct meanings of subject headings. There was little difference between meanings for subject headings in the original and recommended orders of 
subdivisions. However, users were more likely to ascribe a correct meaning to subject headings bearing few subdivisions (less than three) and few words (less than five). Although the findings of the pilot study were interesting, the study had limitations. First, it was difficult for the researchers to determine the meanings of subject headings because the catalogers who assigned meanings to the subject headings used in the study did not agree with one another and the researchers did not agree with the catalogers. Second, the generalizability of pilot study findings was suspect because researchers could not select a random sample of library users for inclusion in the study due to time constraints.

We designed the large-scale study described here to overcome the limitations of the pilot test. In this study, we enlisted an expert cataloger, with many years of experience in LC subject heading assignment, to determine the meaning of subject headings. We recruited a large number of respondents from public libraries to ensure that the study would not be plagued by generalizability questions. We adopted questions, format, procedures, and instructions from the pilot study and revised them based on pilot-study experience.

\section{Data Collection Procedures}

We distributed self-administered questionnaires to children and adults at three public libraries in southeastern lower Michigan. The respondents provided demographic information in the questionnaires, and they were asked to write down the meaning of eight subject headings and to rate the certainty of each meaning.

\section{Constructing SElF-AdMinistered QUESTIONNAIRES}

We selected a total of $24 \mathrm{LC}$ subject headings for inclusion in the study from lists of frequently occurring and randomly selected subject headings from the OCLC Online Computer Library Center, Inc. Online Union Catalog (table 1). Team members deliberately chose subject

\section{TABLE 1}

\section{Subdivided Subject Headings IN THE STUDY}

\section{Subject Heading Set \# 1}

1. Basketball-United States-Records

2. Jews-Michigan-Detroit-History20th century

3. Locomotives-Germany-History

4. Music-500-1400-Philosophy and aesthetics

5. Indians of North America-New Mexico-Food

6. Spanish drama-18th century-History and criticism

7. Education-United States-Finance

8. Art, Modern-California-Los Angeles-20th century-Exhibitions

\section{Subject Heading Set \#2}

9. Housing-United States_Law and legislation

10. Handicapped-Washington (State)Seattle Metropolitan Area-

Transportation

11. Jews-Germany-Berlin-Intellectual life-Congresses

12. Organ music-17th centuryInterpretation (phrasing, dynamics, etc.)

13. World War, 1939-1945-Regimental histories-Japan

14. English poetry-Old English, ca. 450-1100-Modernized versions

15. Music-Washington (D.C.)-History and criticism

16. Art, Modern—20th centuryGermany-Berlin-Exhibitions

\section{Subject Heading Set \#3}

17. Cattle-United States-Marketing

18. Combined sewers-Illinois-Chicago Metropolitan Area-Overflows

19. Art, Modern-20th century-Public opinion

20. Music-Africa-History and criticism-Bibliography

21. Jews-Egypt-Politics and government

22. Music-Louisiana-New OrleansHistory and criticism

23. Education-California-Finance

24. English poetry-Middle English, 1100-1500-Criticism, Textual-Congresses 
headings that were likely to change in meaning when their subdivisions were reordered according to the recommendation of the LC Subject Subdivisions Conference to determine whether end users would in fact notice changes in meaning.

We constructed three separate sets of questionnaires corresponding to three sets of eight subject headings (i.e., subject headings 1-8, 9-16, and 17-24). Six different questionnaires made up each set. Questionnaires within sets varied in terms of the context in which subject headings were presented (i.e., alone, in bibliographic records, or in alphabetical browsing lists), and in terms of the order of subdivisions (i.e., original or recommended order) to minimize the order effect in data collection. Following each of the eight subject headings on questionnaires was a request for respondents to rate the certainty of the meaning they assigned to the subject heading on a scale from 1 (not at all certain) to 7 (very certain).

\section{Recruiting Children and Adults}

We recruited children and adults from three public libraries in southeastern lower Michigan-Flint Public Library, Bacon Memorial District Library, and Livonia Public Library. Flint Public Library has a professional staff of 32 and a collection of more than 500,000 items including government documents, video and audio tapes, microfilms, newspapers, and magazines. The library serves an immediate population of 139,000 within the city of Flint. Because it is the largest library across three counties, patrons come from all over mid-Michigan and beyond.

Bacon Memorial District Library serves 31,000 people in Wyandotte, south of Detroit on the Detroit River in the Downriver area. Downriver is made up of eleven old, established working-class towns, each with its own small library. Most of the population works in manufacturing, mainly in the automobile and steel industries. Wyandotte is a very stable community where often several family generations live close together. The library has a professional staff of 5 and a collection of about 70,000 items, includ- ing magazines, audio and video tapes, reference works on CD-ROM, and maps.

The Livonia Public Library has three branches and a reading room to serve Livonia, the eighth-largest city in Michigan with a population of 100,850 . The library has a professional staff of 21 and a collection of almost 250,000 items. In addition to two public school districts, Livonia is home to Schoolcraft College and Madonna University.

Data collection procedures were similar from library to library. Interviewers stood at the main entrance of the library, introduced themselves to patrons who entered the library, and asked them to take part in the study. They told patrons the name and purpose of the study, explained the voluntary nature of participation, and told them that their complete participation would take ten to fifteen minutes. If patrons declined, interviewers thanked them for stopping, and the patrons continued on their way. Interviewers supplied participating patrons with an unmarked questionnaire, pencil, and eraser, and seated them at a nearby table, where the patrons completed the questionnaires. When finished, participants placed the completed questionnaires in a box provided for that purpose.

Recruiting children was not always as straightforward a process as recruiting adults. If interviewers were unsure whether library patrons were eighteen years old, the patrons were asked how old they were and the patrons were told that the same questionnaires were being given to both to adults and children but that interviewers needed to keep track of the number of each. If women entered the library with small children in tow, interviewers did not approach them to take part in the study because accompanying children could get bored, distracted, or annoyed, and cause their mothers to leave questionnaires incomplete.

Children often needed help with questionnaires. If children asked interviewers what a word meant, the interviewers would give them a simple definition. Interviewers found that it was impossible for children under age ten to complete questionnaires. When inter- 
viewers did give questionnaires to children ten years old or younger, the children usually returned them and said, "I can't do this" or "This is too hard." Some children asked their older sisters, brothers, or parents to help them read the words. Parents read hard words and, in rare cases, provided definitions for words in subject headings. When children asked interviewers for clarification on instructions, interviewers told them to try to put subject heading words together in a sentence or told them to write down what kind of book they thought the subject headings described.

Participants at Flint Public Library, Bacon Memorial District Library, and Livonia Public Library assigned meanings to the first, second, and third sets of eight subject headings, respectively.

\section{OBTAINING CORRECT MEANINGS FOR} SUBdividEd SUBJECT HEAdINGS

Determining how to arrive at correct meanings for the subdivided subject headings used in the study was difficult because we knew that these meanings would be used to judge all the meanings provided by children and adults. We considered using a consensus of responses from professional librarians to determine the meaning of subdivided subject headings. However, results from the pilot test of subject heading understanding demonstrated that professional librarians_-both reference and technical services librarians-did not agree on the meaning of subdivided subject headings (Franz et al. 1994).

After considerable deliberation, we enlisted a single subject-cataloging expert with many years of experience in LC subject heading assignment. We consulted a subject-cataloging expert at the University of Michigan who had more than twenty-five years of experience in LC subject heading practice and many years of service on professional committees in the area of subject access. Not only was the expert familiar with our objectives, she had read the proposal to the organization that funded the study and knew that she would be reviewing subject headings that were not "correct" in terms of the or- der of subdivisions. She completed all 18 versions of questionnaires in several sittings and did not compare subject headings between questionnaires. Although she did not know which headings were correct or incorrect, on occasion she was able to guess which headings were incorrect based on her knowledge of LC subject heading practice.

We undertook a reliability study to ensure that two experts with similar experience would agree on correct meanings. In every case, the second expert's responses corresponded closely in meaning to the responses of the first expert. There were differences in language and syntax but, overall, the second expert gave responses that would be considered correct responses.

\section{analyzing Collected Data}

\section{CATEgorizing User-Assigned MEANINGS}

Three research team members examined user-assigned meanings from completed questionnaires and placed them into correct and incorrect meaning categories and subcategories. Coders first read the expert-supplied meaning and paid close attention to its syntax, language, and meaning. They then read the userassigned meaning on the completed questionnaire and compared it to the expert-supplied meaning. They looked for similarities and differences in language or word choice, syntax, and meaning. They determined whether meanings were "correct" or "incorrect." They then assigned one to two codes to indicate the nature of "correctness" or "incorrectness" of the user-assigned meaning. Details on "correct" and "incorrect" subcategories follow.

\section{Correct Subcategonies}

There were two correct subcategories that coders assigned to correct meanings only: (1) used same language as expert's meaning, and (2) used language that was different from expert's language.

Same Language. If the comparison between the expert-supplied meaning and the user-assigned meaning revealed no 
differences in word choice, syntax, or meaning, coders assigned the user's meaning to the "Same Language" subcategory. An example was the expertsupplied meaning "history of locomotives in Germany" and user-assigned meaning "a history of locomotives in Germany" for the subdivided, reordered subject heading "Locomotives-History-Germany." The coder assigned the "Same Language" subcategory because the user's meaning matched the language of the expert's meaning letter-for-letter except for the initial article.

Different Language. If coders determined that the comparison between the expert-supplied meaning and the userassigned meaning revealed that the respondent used different language to capture the same meaning as the expertsupplied meaning, coders assigned the "Different Language" subcategory. An example was the user-assigned meaning "records (statistics) for U.S. basketball" for the subject heading "BasketballUnited States-Records." The expertsupplied meaning for this subject heading was "records of U.S. basketball."

\section{CORRECT OR INCORRECT SUbCATEGORIES}

There were four subcategories that coders assigned to correct or incorrect meanings: (1) read in one concept, (2) read in more than one concept, (3) used different syntax, and (4) combinations of two correct or two incorrect subcategories. Sometimes the read-in concepts did not affect the meaning of respondentassigned meanings to the extent that they were incorrect compared to expertsupplied meanings and at other times the read-in concepts resulted in incorrect meanings.

Read in One Concept. Coders assigned the subcategory "Read in One Concept" when their comparison of the user-assigned and expert-supplied meanings revealed that the end user added a concept (i.e., a word or phrase). Coders qualified this subcategory to indicate whether the user's addition of a concept resulted in a correct or incorrect meaning for the subdivided subject heading. An example of a user's correct meaning was "fi- nancial aspects of U.S. education" for the subject heading in original order "Education--United States-Finance." The expert-supplied meaning was "finance of U.S. education." The coder assigned the code "Read in One Concept (Correct)" because the user's meaning matched the expert-supplied meaning even though the former contained the concept "financial aspects" that was different from "finance" in the latter.

Here is an example of a meaning that the coder determined was incorrect for the "Read in One Concept" subcategory. The expert-supplied meaning was "transportation of the handicapped in the Seattle (Washington) metropolitan area" for the subject heading "HandicappedWashington (State)-Seattle Metropoli$\tan$ Area-Transportation." The coder assigned the "Read in One Concept (Incorrect)" subcategory to the end user's meaning because the user added the concept "public transportation."

Read in More Than One Concept. Coders assigned the subcategory "Read in More Than One Concept" when their comparison of the user-assigned and expert-supplied meanings revealed that the user added more than one concept (i.e., words or phrases). Coders qualified this subcategory to indicate whether the user's addition of concepts resulted in a correct or incorrect meaning for the subdivided subject heading. An example of a user's correct meaning in this category was "food used (eaten, cooked, etc.) of Indians in New Mexico" for the subject heading "Indians of North AmericaNew Mexico-Food." The expert-supplied meaning was "food of the Indians of New Mexico." The user's addition of more than one concept—“"used," "eaten," and "cooked"-made this meaning appropriate for assignment to the "Read in More Than One Concept (Correct)" subcategory.

An incorrect example in this subcategory follows. The expert-supplied meaning for the reordered subject heading "CattleMarketing-United States" was "marketing of cattle in the U.S." An end user gave the meaning "current or historical cases and techniques for marketing cattle and or beef 
products" to which the coder assigned "Read in More Than One Concept (Incorrect)" because the user's meaning was semantically different from the expert's meaning and included more than one concept (i.e., "current or historical cases," "techniques," and "beef products").

Different Syntax. Coders assigned the "Different Syntax" subcategory when their comparison of the expert-supplied meaning and the respondent-assigned meaning revealed that the respondent used the same language but different syntax to capture the same meaning as the expert-supplied meaning. Coders qualified this subcategory to indicate whether the syntax made the meaning correct or incorrect. An example of a correct meaning with different syntax was the userassigned meaning "Washington (D.C.) music-history and criticism" for the subject heading with subdivisions in recommended order "Music-History and criticism-Washington (D.C.)." The expert-supplied meaning for this subject heading was "history and criticism of Washington (D.C.) music."

Most of the time, different syntax meant an incorrect meaning. An example was the user-assigned meaning "history in Germany of locomotives" given to the subdivided subject heading in original order "Locomotives_Germany-History." The expert-supplied meaning was "history of locomotives in Germany." In this case, the difference in syntax changed the meaning.

Combinations. At times, coders found it impossible to assign only one subcategory to correct or incorrect meanings because more than one situation occurred. For example, the coder assigned "Left Out One Concept (Incorrect)" and "Read in More Than One Concept (Incorrect)" to the user-assigned meaning "a history of Jewish immigrants in Detroit where the majority came from church, work, social problems, and how they are resolving them" for the subject heading "JewsMichigan-Detroit-History-20th century." In this case, the user left out the " 20 th century" element and read in concepts such as "immigrants," "church," and "social problems."

\section{INCORRECT SUBCATEGORIES}

There were three subcategories that coders assigned to incorrect meanings only: (1) left out one concept, (2) left out more than one concept, (3) no response.

Left Out One Concept. Coders assigned the "Left Out One Concept" subcategory when their comparison of the user-assigned and expert-supplied meanings revealed that the user had omitted a concept. Meanings assigned to this subcategory were always incorrect because the omission resulted in an incorrect meaning. For example, the expertsupplied meaning for the subject heading "Housing-United States-Law and legislation" was "law and legislation of housing in the U.S." Coders assigned the "Left Out One Concept" subcategory to the user-assigned meaning "laws on housing in the U.S." because the "legislation" concept was omitted and the omission resulted in an incorrect meaning.

\section{Left Out More Than One Concept.} Coders assigned the "Left Out More Than One Concept" subcategory when their comparison of the user-assigned and expert-supplied meanings revealed that the user had omitted more than one concept. The omission of concepts always changed the meaning of subject headings, thus, this was a subcategory for incorrect meanings. For example, the expert gave the meaning "exhibitions of 20th century Los Angeles (California) modern art" to the subject heading "Art, Modern-California-Los Angeles20th century-Exhibitions." Here are several respondent-assigned meanings missing more than one concept:

- California 20th century

- Art different places

- The new art

- Art in California in the 20th century

No Response. When respondents failed to assign meanings to questionnaires and left the response blank, the coder considered this a null response and coded it as "No Response." Sometimes, users wrote messages telling us about their difficulties. For example, the expert-supplied meaning for the reordered subject heading "English Poetry- Modernized Versions-Old English, ca. 
TABLE 2

Share of AdUlt Patrons by AGE

\begin{tabular}{lcccc}
\hline \hline & $\begin{array}{c}\text { Flint } \\
(\mathrm{n}=46) \\
\%\end{array}$ & $\begin{array}{c}\text { Wyandotte } \\
(\mathrm{n}=48) \\
\%\end{array}$ & $\begin{array}{c}\text { Livonia } \\
(\mathrm{n}=46) \\
\%\end{array}$ & $\begin{array}{c}\text { Total } \\
(\mathrm{n}=140) \\
\%\end{array}$ \\
\hline Age & 17 & 10 & 7 & 12 \\
$18-20$ & 13 & 19 & 4 & 12 \\
$21-30$ & 22 & 29 & 15 & 22 \\
$31-40$ & 30 & 29 & 20 & 26 \\
$41-50$ & 9 & 9 & 22 & 13 \\
$51-60$ & 9 & 4 & 32 & 15 \\
61 and older & 100 & 100 & 100 & 100 \\
Total & & & & \\
\hline
\end{tabular}

450-1100" was "modernized versions of old English (ca. 450-1100) poetry." The respondent wrote down "basically nothing, since I don't know what 'modernized versions' means." Such a meaning was only appropriate for the "No Response" category because the respondent told us why he or she could not supply a meaning.

\section{Characteristics of Participating Children and Adults}

We met our goal of recruiting 48 children and 48 adults at each of the three participating libraries. A total of 144 children and 144 adults took part in the study. Overall, about two-thirds of library patrons who completed questionnaires were female and one-third were male. At Livonia, almost $80 \%$ of participating library patrons were female. The largest percentage of partici- pating males came from Wyandotte, where $41 \%$ of respondents were male.

Table 2 shows ages reported by adult library patrons. (The total number of adults does not amount to 144 in table 2 because some respondents failed to answer the question about age.)

At Flint and Wyandotte, more than half of adults were 18 to 40 years old. At Livonia, only $26 \%$ were in this age range. More than half of Livonia's library patrons were over 50. At Flint and Wyandotte, only $18 \%$ and $13 \%$ of adults were in this age range, respectively.

Table 3 shows children's ages. (The total number of children does not amount to 144 in table 3 because some respondents failed to answer the question about their age.)

The largest percentages of young children came from Flint, where a little more than a third of children were 12 years old or

TABLE 3

Share of Juvenile Patrons by Age

\begin{tabular}{lcccc}
\hline \hline Age & $\begin{array}{c}\text { Flint } \\
(\mathrm{n}=47) \\
\%\end{array}$ & $\begin{array}{c}\text { Wyandotte } \\
(\mathrm{n}=48) \\
\%\end{array}$ & $\begin{array}{c}\text { Livonia } \\
(\mathrm{n}=48) \\
\%\end{array}$ & $\begin{array}{c}\text { Total } \\
(\mathrm{n}=143) \\
\%\end{array}$ \\
\hline 11 and younger & 15 & 13 & 6 & 11 \\
12 & 21 & 4 & 15 & 13 \\
13 & 15 & 23 & 19 & 19 \\
14 & 12 & 4 & 8 & 8 \\
15 & 9 & 8 & 27 & 15 \\
16 & 19 & 21 & 10 & 17 \\
17 & 9 & 27 & 15 & 17 \\
Total & 100 & 100 & 100 & 100 \\
\hline
\end{tabular}


younger. At Wyandotte and Livonia, $17 \%$ and $21 \%$, respectively, of children were 12 years old or younger. About half of Wyandotte children were 16 or 17 years old. Overall, all but one age category (14 years old) registered double-digit percentages.

Overall, one-third of adult library patrons reported that they had attended but not graduated from college. A little over half $(52 \%)$ of participating adults were college graduates. Small percentages $(1 \%$ and $14 \%$ ) of adults had completed only junior and senior high school, respectively. The largest percentage (67\%) of adult library patrons who had a college degree came from Livonia.

Only $5 \%$ of children in the study had graduated from high school or had had some college. A large percentage of children $(38 \%)$ had completed elementary school and a larger percentage of children $(57 \%)$ had completed junior high school.

Questionnaires allowed library patrons to write down a word or phrase that described their profession. About $16 \%$ of adults failed to write down such a word or phrase. We consolidated professions into 12 broad categories. Categories that described $4 \%$ or more of the adults participating in the study were:

- Students $(43 \%)$

- Retired (7\%)

- Education (7\%)

- Homemakers (5\%)

- Science, technology, and computer fields (4\%)

- Tradespersons, e.g., autoworkers, electricians, maintenance workers, cooks $(4 \%)$

At all three libraries, patrons visited the library on a weekly or monthly basis. A breakdown of these percentages for children and for adults shows the same pattern of weekly or monthly library use.

We intended our analysis of demographic information about study participants to be descriptive of the people who took part in the study. Both we and the administrators of participating libraries were sensitive about analyses that compared particular subpopulations of a library's clientele and subject heading understanding because we could not promise that changes to the subject sub- division system could be made that would increase understanding by a particular subpopulation. Consequently, we limited the data analyses in this study to a comparison of subject heading understanding between children and adults generally, and did not extend to other factors such as respondents' ethnic background, gender, socio-economic status, etc.

\section{A Statistical Analysis of Users' Meanings}

\section{CORRECT AND INCORRECT MEANINGS}

Figure 1 shows overall percentages of correct and incorrect meanings for children and adults. Percentages of correct meanings were quite different for the two respondent types. Children provided correct meanings for $31 \%$ of the test headings, while adults provided correct meanings for $39 \%$ of the headings.

To compare the performance of children and adults in terms of assigning correct meanings to subject headings, we submitted collected data to a four-way analysis of variance (ANOVA) with Library, Type of Respondent, and Context as between-subject factors and with Subdivision Order as a within-subject factor. Table 4 summarizes the result of the analysis for main effects. The upper limit for mean correct meanings was 4 because individual respondents gave meanings to four subject headings in original order and to

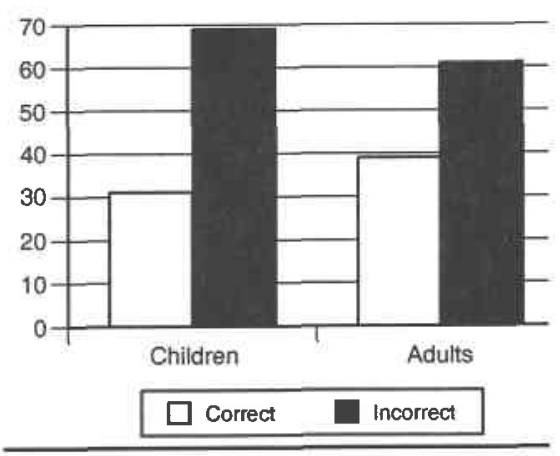

Figure 1. Percent Correct and Incorrect Meanings. 
TABLE 4

Results of Four-way ANOVA For Correct MEANings

Results for Type of Respondent

$\begin{array}{lll}\text { Children } & \text { Mean }=1.24 & \text { Standard deviation }=1.18 \\ \text { Adults } & \text { Mean }=1.57 & \text { Standard deviation }=1.13\end{array}$

$\mathrm{H}_{\mathrm{O}}$ : Type of Respondent effect $-\mathrm{F}_{(1,270)}=10.36-$ Significance $=.001^{\circ}$

Results for Library

$\begin{array}{lll}\text { Flint } & \text { Mean }=1.69 & \text { Standard deviation }=1.15 \\ \text { Wyandotte } & \text { Mean }=0.95 & \text { Standard deviation }=1.06 \\ \text { Livonia } & \text { Mean }=1.57 & \text { Standard deviation }=1.13\end{array}$

$\mathrm{H}_{\mathrm{O}}$ : Library effect $-\mathrm{F}_{(2,270)}=19.82-$ Significance $=.000^{*}$

\section{Results for Context}

\begin{tabular}{|c|c|c|}
\hline Alone & Mean $=1.43$ & Standard deviation $=1.18$ \\
\hline Bibliographic record & Mean $=1.27$ & Standard deviation $=1.17$ \\
\hline Alphabetical list & Mean $=1.51$ & Standard deviation $=1.12$ \\
\hline
\end{tabular}

Ho: No Context effect $-F_{(2,270)}=1.90-$ Significance $=.152$

\section{Results for Subdivision Order}

\begin{tabular}{|c|c|c|}
\hline Driginal order & Mean $=1.45$ & Standard deviation $=1.19$ \\
\hline Recommended order & Mean $=1.36$ & Standard deviation $=1.13$ \\
\hline
\end{tabular}

$H_{0}$ : No Subdivision Order effect $-F(1,270)=1.43-$ Significance $=.234$

-Significant at the .05 level.

four subject headings in the recommended order of subdivisions per questionnaire.

There were significant results for two factors: Type of Respondent and Library. There were no other main effects or interactions that were significant at the .05 level. With respect to Type of Respondent, the means for children and adults varied by a third of a point. Adults therefore performed significantly better than children in terms of assigning correct meanings to subdivided subject headings.

With respect to Library, the means for assigning correct meanings for respondents at Flint and Livonia were about the same; however, the mean for Wyandotte respondents was about two-thirds of a point lower than the means for respondents at the other locations. Because respondents at the three participating libraries examined different sets of subject headings, it was impossible to attribute the effect to the different libraries or the different subject headings enumerated on questionnaires. Thus, no conclusions could be drawn about the significant effect because of confounding factors.

We found no significant effect for Context. Means for the three contexts were slightly different-respondents did best when they assigned meanings to subject headings in alphabetical browsing lists and they did worst when they assigned meanings to subject headings in bibliographic records, but there was a difference of hardly one-quarter of a point between the means. We concluded from this analysis that Context had no effect on respondents' ability to assign correct meanings.

We found no significant effect for Subdivision Order. Less than a tenth of a point separated mean correct meanings for subject headings in the original order and for subject headings in the recommended order. Thus, children and adults performed about as well in terms of assigning correct meanings whether they examined subject headings in the original order or in the recommended order of subdivisions. This surprised us. The impetus for this research was a recommendation to standardize the 


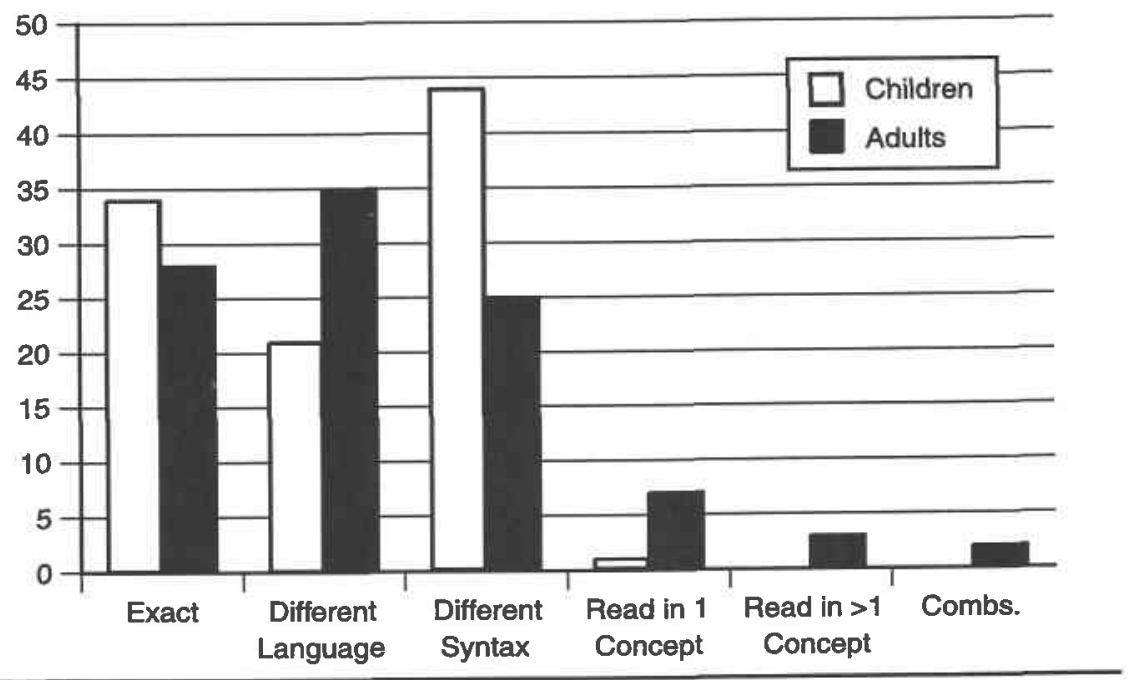

Figure 2. Percentages of Correct Meaning Subcategories by Age.

order of subdivisions. Some members of the ALA subcommittee studying the problem of subdivision order felt that standardizing the order of subdivisions might confuse library users and adversely affect their ability to give correct meanings to subdivided subject headings. The result here demonstrated that changing the order of subject subdivisions did not have a negative impact on library users and their understanding of subject headings.

\section{A Failure Analysis of End Users' Meanings}

This failure analysis of end users' meanings features the specific reason or reasons why end users' meanings were correct or incorrect using the subcategories into which team members assigned users' meanings.

\section{Correct MEANing SubCategories}

Figure 2 shows that the patterns of percentages of correct subcategories for children's and adults' meanings were rather different. Children's correct meanings usually were exact representations of the expert's meanings or used different syntax. Children used different language but syntax and exact matches were more likely. Children rarely gave correct meanings that read in concepts. In contrast, the largest percentage of adults' correct meanings used different language. Adults also used different syntax and matched the expert's meanings exactly. On occasion, adults gave correct meanings that read in concepts.

Here are three examples of subject headings for which both children and adults matched the expert's meanings.

- Locomotives-Germany-History / history of locomotives in Germany

- Cattle--United States-Marketing / marketing of cattle in the United States

- Jews-Egypt-Politics and government / politics and government of Jews in Egypt

Meanings assigned to the "Different Language (Correct)" subcategory accounted for $21 \%$ of children's correct meanings and $35 \%$ of adults' correct meanings. Table 5 lists subject headings, expert-supplied meanings, and examples of library users' meanings in this subcategory.

Meanings assigned to the "Different Syntax (Correct)" subcategory accounted for $44 \%$ of children's correct meanings and $25 \%$ of adults' correct meanings. Table 6 gives examples of library users' meanings in this subcategory. 
TABLE 5

Correct Meanings in the “Different Language" Subcategory

\begin{tabular}{|c|c|c|}
\hline Subject Headings & Expert's Meaning & Library Users' Meanings \\
\hline $\begin{array}{l}\# 1: \text { Basketball- } \\
\text { Records-United } \\
\text { States }\end{array}$ & $\begin{array}{l}\text { Records of U.S. basketball } \\
\text { Records of basketball in } \\
\text { repositories in the U.S. }\end{array}$ & $\begin{array}{l}\text { United States basketball teams, } \\
\text { scores, and other game stuff } \\
\text { Basketball statistics in the U.S. }\end{array}$ \\
\hline $\begin{array}{l}\text { \#2: Jews-History- } \\
\text { Michigan- } \\
\text { Detroit-20th } \\
\text { century }\end{array}$ & $\begin{array}{l}\text { History of } 20 \text { th century } \\
\text { Detroit (Mich.) Jews }\end{array}$ & $\begin{array}{l}\text { History of Detroit's Jewish } \\
\text { community in this century } \\
\text { History of Jews who lived in } \\
\text { Detroit, Mich., during the } 20 \text { th } \\
\text { century }\end{array}$ \\
\hline $\begin{array}{l}\text { \#17: Cattle-United } \\
\text { States-Marketing }\end{array}$ & $\begin{array}{c}\text { Marketing of cattle in } \\
\text { the U.S. }\end{array}$ & $\begin{array}{l}\text { The selling of cattle in the U.S. } \\
\text { Information on marketing of } \\
\text { cattle in the U.S. } \\
\text { How cattle are marketed } \\
\text { in the U.S. }\end{array}$ \\
\hline
\end{tabular}

Both children and adults seldom gave correct meanings that read in concepts. Examples for the subject heading "English poetry-Modernized versions-Old English, ca. 450-1100" to which the expert assigned the meaning "modernized versions of old English (ca. 450-1100) poetry" are:

- English poetry translated to modern version from old English, ca. 450-1100

- Modern English versions of English poetry written between $450-1100$

- English poetry between 450-1100 ca. that has been updated so that [it] is readily understandable to the average Joe

The first two meanings read in the "translated" and "written" elements and the last meaning read in the story about the "average Joe." These read-in elements did not make the meanings incorrect but they did clarify the meaning.

\section{InCORReCt MEANing SubCategories}

Figure 3 shows percentages of incorrect subcategories for library users' meanings. In this instance, patterns for children and adults were not that much different. Percentages were highest for "Different Syntax" but there were also high percentages of incorrect meanings for leaving out one or more concepts and reading in one concept. There were small percentages for reading in more than one concept, combinations, and no responses.

TABLE 6

CoRrect MEANings in the “DifFERENT SyntaX" SubCategory

\begin{tabular}{lcc}
\hline Subject Headings & \multicolumn{1}{c}{ Expert's Meaning } & Library Users' Meanings \\
\hline \#1: $\begin{array}{l}\text { Basketball- } \\
\text { United States- }\end{array}$ & Records of U.S. basketball & $\begin{array}{c}\text { U.S. basketball records } \\
\text { The basketball records } \\
\text { of the U.S. }\end{array}$ \\
\hline $\begin{array}{l}\text { R4: } \begin{array}{l}\text { Music- } \\
\text { Philosophy and } \\
\text { aesthetics- }\end{array} \\
500-1400\end{array}$ & $\begin{array}{c}\text { Philosophy and aesthetics } \\
\text { of music for the time } \\
\text { period 500-1400 }\end{array}$ & $\begin{array}{c}\text { Music philosophy and } \\
\text { aesthetics from } 500-1400 \\
\text { The philosophy and aesthetics } \\
\text { of music in the time period } \\
500-1400\end{array}$ \\
\hline
\end{tabular}

\#7: Education-United

States-Finance
Finance of education in the U.S.
U.S. finances education

Education finance in the U.S. 


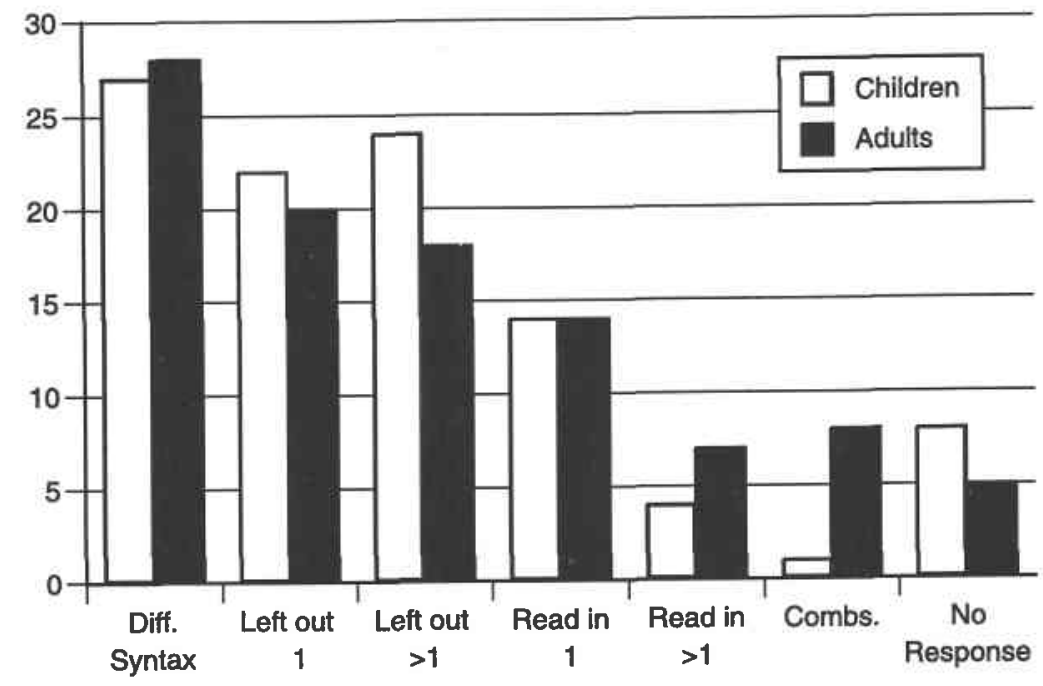

Figure 3. Percentages of Incorrect Meaning Subcategories by Age.

The response pattern in figure 3 summarizes the percentages of incorrect meaning subcategories across all three sets of subject headings; however, response patterns were quite different for each of the three sets of subject headings. For example, children's meanings were characterized by a high percentage $(43 \%)$ of "Left Out More Than One Concept" meanings for the second set of subject headings. Adults' meanings featured moderately high percentages of "Left Out One Concept" (22\%), "Left Out More Than One Concept" (23\%), and "Read in One Concept" $(24 \%)$ meanings for the third set of subject headings. The sub-sections that follow examine the specific problems children and adults experienced.

\section{Syntax Problems}

Incorrect meanings with "Different Syntax" were typical of subject headings to which the expert gave different meanings to the two different forms of subject headings. Users assigned incorrect meanings to subject headings that would have been judged correct for the other order of the subject heading. For example, the expert supplied the meaning "public opinion of 20 th century modern art" to the subject heading
"Art, Modern-20th century-Public opinion" in the original order of subdivisions and she assigned the meaning "20th century public opinion of modern art" to the subject heading "Art, Modern-Public opinion-20th century" in the recommended order of subdivisions. Respondents assigned the former meaning to the latter subject heading and vice versa. Table 7 lists three more subject headings that gave users the same type of syntax problem.

This type of syntax problem did not occur for every subject heading for which changing the order of subdivisions also changed the subject heading's meaning. Nor did all the children or all the adults who gave meanings to these subject headings generate incorrect meanings with this particular type of syntax problembut it did happen with some frequency.

"Different Syntax (Incorrect)" meanings sometimes introduced entirely new meanings for subject headings that were not amongst the one or more meanings supplied by the expert. For example, the expert gave the subject heading "Education-United States-Finance" in the original and recommended orders only one meaning-"finance of U.S. education." Examples of meanings with syntax 
TABLE 7

“Different Syntax (InCoRrect)" MEanings

\begin{tabular}{lcc}
\hline \hline Subject Headings & Expert's Meanings & Library Users' Meanings \\
\hline Spanish drama-History & History and criticism & 18th century history and \\
and criticism-18th century & $\begin{array}{c}\text { of } 18 \text { th century } \\
\text { Spanish drama }\end{array}$ & $\begin{array}{c}\text { cricism for Spanish drama } \\
\text { 18th century history and } \\
\text { criticism of Spanish drama }\end{array}$ \\
\hline
\end{tabular}

$\begin{array}{lc}\text { Spanish drama-18th } & \text { 18th century history } \\ \text { century-History and } & \text { and criticism of } \\ \text { criticism } & \text { Spanish drama }\end{array}$

History and criticism of 18 th century Spanish drama

18th century Spanish drama, a history and criticism of

$\begin{array}{lc}\text { Art, Modern-20th } & \text { Exhibitions of 20th } \\ \text { century-California-Los } & \text { century modern art from } \\ \text { Angeles-Exhibitions } & \text { Los Angeles, Calif. }\end{array}$

Modern art exhibitions of 20th century in Los Angeles, Calif.

20th century Los Angeles,

Calif., exhibitions in modern art

Modern art in the 20th century in Los Angeles

\begin{tabular}{lc}
\hline Art, Modern-20th & Exhibitions of 20th \\
century-California-Los & century Los Angeles \\
Angeles-Exhibitions & (Calif.) modern art
\end{tabular}

Exhibitions of modern art in Los Angeles during the 20th century

20th century exhibitions in Los Angeles, Calif., about modern art

$\begin{array}{lc}\text { Art, Modern-Public } & \text { 20th century public } \\ \text { opinion-20th century } & \text { opinion of modern art }\end{array}$

Public opinion of 20 th century modern art

Public opinion about 20th century (modern) art

What the public thinks about 20 th century modern art

How the general public feels about modern art in the 20th century

\begin{tabular}{lcc}
\hline $\begin{array}{l}\text { Art, Modern-20th } \\
\text { century-Public opinion }\end{array}$ & $\begin{array}{c}\text { Public opinion of 20th } \\
\text { century modern art }\end{array}$ & $\begin{array}{c}\text { 20th century public opinion } \\
\text { of modern art }\end{array}$ \\
\hline
\end{tabular}

problems that gave entirely new meanings to this subject heading were:

- U.S. education in finance

- Finance education in the U.S.

- U.S. finance education

- Education and finance in the U.S.

\section{LEAVING OUT CONCEPTS}

Incorrect meanings for "Leaving Out One Concept" were more typical of adults than children. Children also left out concepts but they were more likely to leave out two or more concepts. Table 8 features the many meanings assigned to four subject headings that were missing more than one concept. Most of the examples in table 8 came from children.

Users consistently missed the "combined" element in the "Combined sew- ers" subject heading. They usually glossed over this concept by referring to "sewer problems" or "information on sewers" in their meanings. The "regimental histories" element was consistently missing from the examples for the "Japanese regimental histories" heading. Some respondents also left out the "Japanese" element.

Users did not consistently omit certain topics from their meanings for the other two subject headings. For example, meanings for the "Housing" heading left out one or more of the four concepts in this subject heading, i.e., "housing," "law," "legislation," and "U.S." Overall, we could characterize incorrect meanings for "left out concepts" in two ways: (1) 
TABLE 8

InCORRECT MEANINGS IN THE “LEFT OUT MORE THAN ONE CONCEPT" SUBCATEGORY

\begin{tabular}{|c|c|c|}
\hline Subject Headings & Expert's Meanings & Library Users' Meanings \\
\hline $\begin{array}{l}\text { Housing-United } \\
\text { States-Law and } \\
\text { legislation }\end{array}$ & $\begin{array}{l}\text { Law and legislation of } \\
\text { U.S. housing }\end{array}$ & $\begin{array}{l}\text { Types of housing } \\
\text { Congress } \\
\text { Housing in the U.S. } \\
\text { Government } \\
\text { The laws for a house } \\
\text { (rental or own) } \\
\text { Law and legislation }\end{array}$ \\
\hline $\begin{array}{l}\text { World War, 1939-1945- } \\
\text { Regimental histories- } \\
\text { Japan }\end{array}$ & 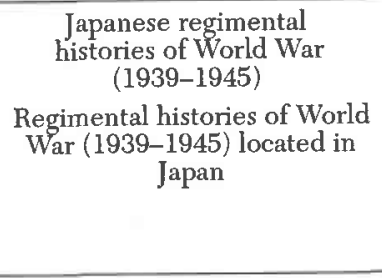 & $\begin{array}{c}\text { WWII-concerning Japan } \\
\text { Boundaries war related } \\
\text { History of military } \\
\text { Things that went on in WWII } \\
\text { Wars } \\
\text { The war against Japan } \\
\text { Japan and the world wars }\end{array}$ \\
\hline $\begin{array}{l}\text { Music_-Washington } \\
\text { (D.C.)_History and } \\
\text { criticism }\end{array}$ & $\begin{array}{l}\text { History and criticism of } \\
\text { Washington (D.C.) music }\end{array}$ & $\begin{array}{l}\text { Music reflecting history } \\
\text { Music peculiar to } \\
\text { Washington, D.C. } \\
\text { Congress } \\
\text { History of music } \\
\end{array}$ \\
\hline $\begin{array}{l}\text { Combined sewers- } \\
\text { Illinois-Chicago } \\
\text { Metropolitan Area- } \\
\text { Overflows }\end{array}$ & $\begin{array}{l}\text { Overflows of combined } \\
\text { sewers in the Chicago } \\
\text { (Ill.) metropolitan area }\end{array}$ & $\begin{array}{c}\text { Where there is a "problem" with } \\
\text { overflow of sewers } \\
\text { Information on the sewers of } \\
\text { Chicago, Ill. } \\
\text { Sewer flow in Chicago } \\
\text { The unique sewer problems of } \\
\text { the Chicago area }\end{array}$ \\
\hline
\end{tabular}

meanings that captured two or more of the several specific concepts present in the subject, e.g., "music peculiar to Washington, D.C." and "history of music" for the "Music" subject heading in table 8 , and (2) meanings that described the heading in one or two broad terms, e.g., "the war against Japan," "Japan and the world wars," and "wars" for the "World War" subject heading in table 8 .

\section{READING IN CONCEPTS}

Reading in concepts occurred infrequently. The subject headings to which some patrons assigned "read-in" meanings were also likely to inspire other patrons to generate meanings with syntax errors or to leave out one or more concepts.
The concepts that patrons read into their meanings were rarely concepts that were present in the bibliographic records or alphabetical browsing lists that were displayed along with the subject heading. An examination of user-assigned meanings for the subject heading "Basketball-United States-Records" resulted in examples of meanings that contained read-in concepts in addition to elements present in the expert's meaning "Basketball records in the U.S." Examples of users' meanings were:

- The records of the basketball players in the U.S.

- Athletic record holders in basketball

- I would find facts relating to basketball records made or broken in the U.S.

- NBA player and team statistics 
TABLE 9

SUbJECT HEADINGS AND BLANK RESPONSES

\begin{tabular}{|c|c|c|}
\hline Subject Heading & No Response (\%) & No. of Meanings \\
\hline \#4: Music_Philosophy and aesthetics-500-1400 & 35 & 1 \\
\hline $\begin{array}{l}\text { \#24: English poetry-Middle English, } \\
\text { 1100-1500-Criticism, Textual-_Congresses }\end{array}$ & 22 & 2 \\
\hline \#21: Jews-_Egypt-_Politics and government & 13 & 2 \\
\hline $\begin{array}{l}\text { \#11: Jews-Cermany-Berlin-Intellectual } \\
\text { life-Congresses }\end{array}$ & 12 & 2 \\
\hline \#23: Education-California-Finance & 11 & 1 \\
\hline $\begin{array}{l}\text { \#15: Music-Washington (D.C.)-History and } \\
\text { criticism }\end{array}$ & 11 & 3 \\
\hline $\begin{array}{l}\text { \#22: Music-Louisiana-New Orleans-History and } \\
\text { criticism }\end{array}$ & 10 & 3 \\
\hline
\end{tabular}

The read-in concepts in these user-assigned meanings probably reflected users' own personal knowledge of and experience with this subject. Some read-in concepts might have also been inspired by the bibliographic record's title (Basketball Statistics: Top Players and Teams by Game, Season, and Career) because the users mentioned basketball players, teams, and the NBA. Here are more user-assigned meanings with read-in concepts for the subject heading "Cattle-United StatesMarketing." The expert's meaning for this subject heading was "marketing of cattle in the U.S."

- Making money-dealing in cattle/ U.S.

- How to market cattle profitably in U.S. by knowing cattle cycles

- Law and legislation regarding cattle marketing in U.S.

- How the USDA goes about marketing cattle

The title of the bibliographic record (Cattle Cycles: How to Profit From Them) could have inspired the first two meanings listed above. Patrons who formulated the last two titles above did not see the subject heading in a bibliographic record. They could have added the phrases "law and legislation" and "USDA" based on their own experiences and knowledge.

\section{No RESPONSE}

We categorized more than $10 \%$ of the responses for seven subject headings into the "no response" subcategory. Because we had about 50 meanings per subject heading from children and 50 meanings per subject heading from adults, this meant that five children or adults failed to provide meanings for these subject headings. These seven subject headings are listed in table 9 along with the percentages of "no responses" and the number of meanings for the six representations of the subject heading.

Most percentages were around $12 \%$, but there were two percentages that accounted for much more. Two of the seven subject headings featured only one meaning while another two featured as many as three meanings.

We looked at the other incorrect meanings users assigned to the subject headings in table 9. Respondents were also likely to assign to these subject headings incorrect meanings that either left out or read in one or more concepts. Both children and adults typically left out one or more concepts when assigning meanings to the subject heading "Jews-Germany-BerlinIntellectual life-Congresses." Examples of children's meanings were:

- Religion

- About different kinds of people

- A Jew's life

- About Germany

- How Jewish people live their life Read-in concepts for these headings were typical of the incorrect meanings users gave to the subject heading "Educa- 


\section{LRTS • 43(3) - End-User Understanding of Subject Headings}

tion-California-Finance." Some of the concepts children and adults read into their meanings might have come from the bibliographic record in which they saw this subject heading which contained the concepts "school" and "budget." Examples of incorrect meanings with read-in concepts were:

- Cost of education in California

- California school budget

- How much they waste money on education in California

- How to finance your education in California

- Education on young kids and teens (in California)

\section{Certainty of Correct Meanings}

Respondents were not only asked to write down the meaning of subject headings, they were asked to rate the certainty of their meanings on a scale from 1 (not at all certain) to 7 (very certain). Overall, children gave certainty scores that averaged 5.05 for correct meanings. They gave certainty scores that averaged 4.15 for incorrect meanings. Their average certainty score for correct meanings was higher than their average certainty score for incorrect meanings and a little less than one point separated the two scores. Figure 4 shows average certainty scores that children gave to correct and incorrect meanings of subject headings for each of the three sets of subject headings. Children's certainty scores for correct meanings were always higher than their certainty scores for incorrect meanings. The difference between certainty scores for correct and incorrect meanings varied by as little as about a half point (set 3 ) and as much as about one point (sets 2 and 3 ).

Certainty scores for the two orders of subdivisions or three contexts of subject headings mirrored the general trend that certainty scores for correct meanings were greater than such scores for incorrect meanings. This was not true across the board for certain contexts and orders of subdivisions, as percentages of correct and incorrect meanings flip-flopped.

Overall, adults gave certainty scores that averaged 5.70 for correct meanings.

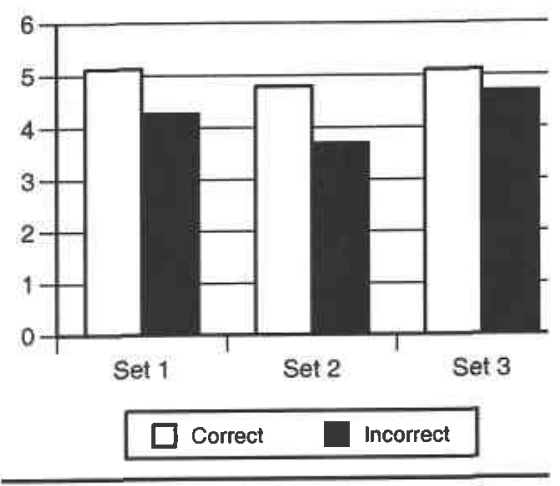

Figure 4. Children's Certainty Scores.

They gave certainty scores that averaged 5.08 for incorrect meanings. The average certainty scores that adults gave to correct and incorrect meanings were three- quarters of a point to almost a full point higher than the average certainty scores that children gave to correct and incorrect meanings. Figure 5 shows average certainty scores that adults gave to correct and incorrect meanings of subject headings for each of the three sets of subject headings.

Adults' certainty scores for correct meanings were higher than their certainty scores for incorrect meanings for the three subject headings sets. The difference between certainty scores for correct and incorrect meanings varied by as little as about a half point (sets 1 and 3) and as much as about one point (set 2).

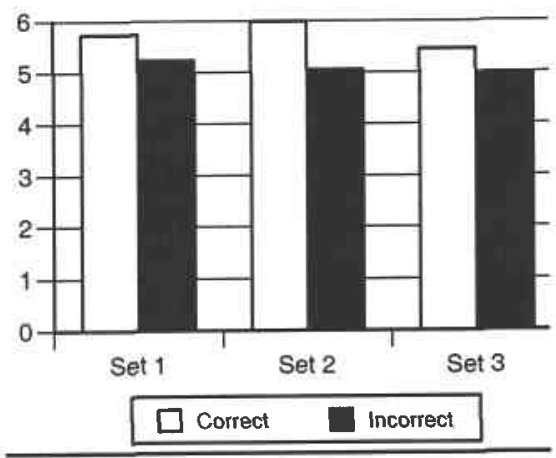

Figure 5. Adults' Certainty Scores. 
Certainty scores for the two orders of subdivisions or three contexts of subject headings again mirrored the general trend that certainty scores for correct meanings were greater than such scores for incorrect meanings. Sometimes the difference between two scores was very low (just a few hundredths of a point separating the two certainty scores) and sometimes the difference exceeded a point.

Generally unusually high or low certainty scores were not associated with a particular correct or incorrect meaning code. We found one exception. Unusually low certainty scores were almost always associated with both incorrect left-out subcategories.

\section{Discussion AND IMPLICATIONS of STUdY Findings}

In this section, we discuss the findings in terms of the five research questions we sought to answer.

1. Do users understand subject headings? Overall, about $36 \%$ of the meanings end users gave to subdivided subject headings were correct. Some readers might conclude that this percentage was low. But the subdivided subject headings to which end users assigned meanings were complex. Some subject headings had as many as three to four subdivisions. Other subject headings featured one or more main headings or subdivisions that were inverted, contained more than one phrase, or featured subdivisions with qualifiers.

In addition, the rules that coders followed to determine whether meanings were correct and incorrect were rather stringent. Study participants had to provide meanings that contained all elements present in the expert's meaning. The syntax of their meanings had to match the syntax of the meanings supplied by the expert. If users formulated meanings that included additional elements besides those present in expert-supplied meanings, their meanings were usually marked incorrect.

Furthermore, we have no basis for comparison. To our knowledge, this is the first large-scale study of end-user understanding of subject headings. If findings from other studies were available, we might be able to compare percentages of correct meanings and determine just how low or how high these scores were.

2. Does end-user understanding vary based on subject heading context? Mean correct meanings for the three contexts varied very little. End users did best ( mean $=1.51$ ) when they assigned meanings to subject headings in alphabetical browsing lists, and they did worst (mean $=1.27$ ) when they assigned meanings to subject headings in bibliographic records (table 4). But there was hardly one-quarter of a point difference between the means, and the difference was not significant. On occasion, we noticed that library patrons added concepts to their meanings that occurred in bibliographic records, but this did not happen very frequently. When it did happen, adults rather than children were usually the ones giving meanings with read-in concepts.

\section{Does end-user understanding} vary based on subject heading order? This research question was one of our most important because the impetus for this study was a recommendation to standardize the order of subdivisions (Conway 1992). Before implementing the recommendation, librarians wanted to determine whether reordering subdivisions would have a negative effect on end users' understanding of subdivided subject headings. Some librarians expected that end users would have more problems understanding the meaning of subject headings in the recommended order than in the original order.

Less than a tenth of a point separated the two mean correct meanings for subject headings in the original (1.45) and recommended (1.36) orders. Analysis of Variance demonstrated that library users performed about as well in terms of assigning correct meanings whether they examined subject headings in original order or in the recommended order of subdivisions (table 4).

4. Are there differences in understanding between children and adults? Figure 1 showed that percentages of correct meanings were quite different for children and adults-31\% of children's 
meanings were correct and 39\% of adults' meanings were correct. Although mean correct meanings for children (1.24) and adults (1.57) varied by only a third of a point, Analysis of Variance demonstrated that there was a significant difference between the two means (table 4). Adults did significantly better than children in terms of assigned correct meanings to subdivided subject headings.

Findings about certainty scores were heartening. They demonstrated that both children and adults had less confidence in their incorrect meanings than in their correct meanings.

5. What changes should be made to LCSH and other controlled vocabularies to improve user understanding? Do the data and analyses presented here suggest making major changes to the existing system of subject headings based on end users' lack of understanding and difficulty with subject headings? We feel that the library community needs to grapple with the issues involved with answering this question and make some important decisions.

The statistical analysis did not result in a significant main effect for Subdivision Order. Thus, children and adults performed about as well in terms of assigning correct meanings regardless of the order of subdivisions in subject heading strings. Because subdivision order did not negatively affect end-user understanding, we recommend standardizing the order of subject subdivisions. Standardizing subdivision order would simplify cataloging and save money. Library school faculty and technical services staff would not have to spend time training students and staff how to order the subdivisions in subject heading strings. Cataloging would be streamlined because staff would no longer spend time determining the order of subject subdivisions. Instead, they would build strings based on a standardized order of subdivided elements or they would merely select the individual subject heading elements and let a computer program build the subdivided strings. A standardized order of subdivision elements could also lead to a reduction in the number of errors that are due to subdivision order (Drabenstott and Vizine-Goetz 1994).
We do not believe that more studies would reveal different degrees of understanding among users. There is sufficient basis on which to determine that the order of subdivisions could be standardized without great loss of meaning.

If members of the library community are disturbed at the low levels of end-user understanding described here, then they should begin to consider making more drastic changes, possibly, along the lines suggested by Cochrane (1984). She recommended breaking up long subdivided subject headings and defended her recommendation saying that "the logic behind the string's construction is lost on most catalog users" (Cochrane 1986, 62). Now we have empirical evidence to support her claim.

If the library community does not make changes to the existing system, we have other recommendations that LC could introduce to improve end-user understanding. LC should consider involving people who are heavy users of the system-children, adults, and reference librarians-in the establishment of new subject headings and subdivisions in the LCSHsystem. Several types of consultation are possible. LC could sponsor clubs, committees, working groups, etc., of children and adults who would serve in an advisory capacity to the Cataloging Policy and Support Office (the editorial board for $L C S H$ ). Although children and adults could be recruited from nearby high schools or public libraries or could be frequent public users that LC's reference librarians have come to know, they could be recruited from afar and use electronic mail or other collaboration technologies to assist staff of the Cataloging Policy and Support Office. Also such staff could review published material on a subject across several different intended audiences to find language shared by audiences to express subjects. Surely staff of the Cataloging Policy and Support Office would have their own ideas about recruitment. It is important to include library catalog users - children, adults, and reference librarians-in the process.

Future researchers could experiment with introducing certain indicators to subject headings that would reduce the 
problems library patrons have understanding subject headings due to syntax. Unfortunately, librarians would have to teach patrons how such indicators worked. They would be unable to reach all patrons to explain the system, and those patrons they did reach would probably forget the explanation rather quickly.

The punctuation between subject heading elements could be examined. Most catalogs combine such elements using two hyphens (-) or an em dash (-). Researchers could experiment with colons (:), slashes $(/)$, or tildes $(\sim)$ between elements. In recent years, the principal researcher of this study has overheard new students or faculty colleagues in related fields explain how the LC subject subdivisions system works. They almost invariably describe a system in which the individual elements in subdivided subject headings are ordered in a hierarchical relationship. Perhaps researchers would consider undertaking studies that introduce different punctuation between subject heading elements to determine what impact such elements have on subject heading understanding.

\section{CONCLUSION}

It is time for the library community to grapple with difficult questions about its subject-access system and make informed decisions about solving the problem of low levels of end-user subject heading understanding. Subject analysis and its representation by LCSH have been the primary means of subject access in library catalogs for more than one hundred years. Practical reasons-including the enormity of the investment in this systemsuggest it will continue into the next century. The findings of research into end-user understanding is an important source of information that can assist LC and subject catalogers in making decisions that contribute to the effectiveness of cataloging and the subject headings.

\section{WoRKs CITED}

Bates, Marcia J. 1977. Factors affecting subject catalog search success. Journal of the American Society for Information Science 28: 161-69.
Chan, Lois Mai. 1986. Library of Congress Subject Headings: Principles and application. $2 \mathrm{~d}$ ed. Littleton, Colo.: Libraries Unlimited.

Chan, Lois Mai. 1995. Library of Congress Subject Headings: Principles and application. 3d ed. Littleton, Colo.: Libraries Unlimited.

Cochrane, Pauline A. 1986. Improving LCSH for use in online catalogs. Littleton, Colo.: Libraries Unlimited.

- 1984. Modern subject access in the online age. American libraries 15: 80-83, $145-50,250-55,336-39,438-42$.

- 1983. LCSH entry vocabulary project: Final report to the Council on Library Resources and to the Library of Congress. Arlington, Va.: ERIC Document Reproduction Service, ED 233746.

Conway, Martha O'Hara, ed. 1992. The future of subdivisions in the Library of Congress Subject Headings system: Report from the Subject Subdivisions Conference sponsored by the Library of Congress, May 9-12, 1991. Washington, D.C.: Library of Congress Cataloging Distribution Service.

Cooperative Subject Cataloging Project. 1991. Cooperative subject cataloging project: Summary of records processed through September 1991. 4 pp. (Photocopy.)

Cutter, Charles A. 1904. Rules for a dictionary catalog. 4th ed. Washington, D.C.: U.S. Government Printing Office.

Drabenstott, Karen M., and Diane VizineGoetz. 1994. Using subject headings for online retrieval: Theory, practice, and potential. San Diego, Calif.: Academic Pr.

Franz, Lori, et al. 1994. End-user understanding of subdivided subject headings. Library resources \& technical services 38 : 213-26.

Haykin, Donald Judson. 1951. Subject headings: A practical guide. Washington, D.C.: Library of Congress.

Lester, Marilyn Ann. 1989. Coincidence of user vocabulary and Library of Congress Subject Headings: Experiments to improve subject access in academic library online catalogs. Ph.D. dissertation, University of Illinois at Urbana-Champaign.

Library of Congress. 1991. Subject cataloging manual: Subject headings. Washington, D.C.: Cataloging Distribution Service.

Lilly, Oliver L. 1954. Evaluation of the subject catalog: criticism and a proposal. American documentation 5 (April): 41-60.

Miksa, Francis. 1983. The subject in the dictionary catalog from Cutter to the present. Chicago: American Library Association. 